\title{
Pseudolaric acid B inhibits neuroglioma cell proliferation through DNA damage response
}

\author{
FENGMEI SONG ${ }^{1,2^{*}}$, XIAOYAN YU ${ }^{2 *}$, HAIPENG ZHANG ${ }^{3}$, ZENGYAN WANG $^{4}$, \\ YUE WANG $^{5}$, XIANGLING MENG ${ }^{2}$ and JINGHUA YU ${ }^{1}$ \\ ${ }^{1}$ Institute of Virology and AIDS Research, The First Hospital of Jilin University, Jilin University, Changchun, Jilin 130021; \\ ${ }^{2}$ Department of Experimental Pharmacology and Toxicology, School of Pharmacy, Jilin University; \\ Departments of ${ }^{3}$ Gynaecology and ${ }^{4}$ Internal Medicine, The First Hospital of Jilin University, Jilin University; \\ ${ }^{5}$ Chemistry of Traditional Chinese Medicine, College of Pharmacy, Changchun University of Chinese Medicine, \\ Changchun, Jilin 130000, P.R. China
}

Received January 5, 2017; Accepted July 20, 2017

DOI: 10.3892/or.2017.5861

\begin{abstract}
Human neuroglioma is one of the most common malignant intracranial tumors in neurosurgery, and accounts for more than $50 \%$ of all brain cancer cases. Thus, a clinically effective drug with which to treat neuroglioma is urgently required. Pseudolaric acid B (PAB), a diterpene acid isolated from the root and trunk bark of Pseudolarix kaempferi Gordon (Pinaceae), was found to inhibit cell growth in a variety of cancer cell lines, but to date the effect of PAB on neuroglioma remains unclear. MTT analysis confirmed that PAB inhibited neuroglioma A172 cell growth in a time- and dose-dependent manner. In addition, PAB influenced the aggregation of tubulin in A172 cells. Meanwhile following PAB treatment, a higher percentage of cells accumulated in the G2/M phase from 12 to $48 \mathrm{~h}$, while at $36 \mathrm{~h}$, cell cycle slippage into the G0/ $\mathrm{G} 1$ phase, and at $48 \mathrm{~h}$, slippage into the $\mathrm{S}$ phase was observed using flow cytometric analysis. Corresponding protein expression was consistent with the cell cycle alteration as detected by western blotting, and it was speculated that cell cycle slippage was related to reduced effectiveness of PAB which warrants further investigation. Meanwhile PAB induced cell death by regulating p38, ERK and JNK expression and activating the DNA damage response. Therefore, PAB plays an antitumor role in A172 cells, and may be a candidate drug for neuroglioma therapy.
\end{abstract}

Correspondence to: Dr Jinghua Yu, Institute of Virology and AIDS Research, The First Hospital of Jilin University, Jilin University, 519 Dongming Zhu Street, Changchun, Jilin 130021, P.R. China E-mail: yjh-0-2002@163.com

${ }^{*}$ Contributed equally

Key words: pseudolaric acid B, apoptosis, cell cycle arrest, neuroglioma

\section{Introduction}

Pseudolaric acid B (PAB) is a diterpene acid isolated from the root and trunk bark of Pseudolarix kaempferi Gordon (Pinaceae), known as 'Tu-Jin-Pi' in Chinese. PAB has been used to treat dermatological fungal infections. PAB was found to exert potent inhibitory activity on cell growth in vitro in various tumor cell lines (1-6) through cell cycle arrest, apoptosis or autophagy. However, to date the role of PAB in neuroglial cells is not clear.

Human neuroglioma is one of the most common malignant intracranial tumors in neurosurgery, and accounts for more than $50 \%$ of all brain cancer cases, and is recently diagnosed in a younger population $(7,8)$. The pathogenesis of neuroglioma is related to multiple processes affected by dozens of regulatory factors (9); however, our knowledge concerning the underlying factors regulating neuroglioma progression remains unknow, and clinically effective drugs to treat neuroglioma are urgently required.

The DNA damage response, caused by a variety of stimuli, arrests the cell cycle to allow damage repair or direct cell apoptosis (10). Apoptosis, as one type of antitumor mechanism, has been a focus of numerous studies for antitumor drug development $(11,12)$. In mammalian cells, the MAPK pathway is involved in cell proliferation or cell death: stress-activated protein kinase/c-Jun-N-terminal kinase (Sapk/Jnk), p38 kinase and extracellular signal-regulated kinase (Erk) (13). Generally, Erk protein promotes inflammation, apoptosis, growth, differentiation, oncogenic transformation, while Jnk and p38 are implicated in growth, differentiation and development $(14,15)$. Cell cycle arrest is important after eukaryotic normal cell cycle progression is affected. These regulatory pathways are commonly referred to as cell cycle checkpoints (16). Cells are arrested at cell cycle checkpoints temporarily to allow for: i) cellular damage to be repaired; ii) the dissipation of an exogenous cellular stress signal; or iii) the availability of essential growth factors, hormones or nutrients.

In the present study, we showed that PAB inhibited neuroglioma cell proliferation and cell migration through influencing tubulin aggregation. Meanwhile, PAB further 
Table I. Primers for real-time PCR.

\begin{tabular}{llll}
\hline Primer pair & \multicolumn{1}{c}{ Role } & \multicolumn{1}{c}{ Forward sequence 5'-3' } & \multicolumn{1}{c}{ Reverse sequence 5'-3' } \\
\hline Cyclin E & Real-time & TCAGGGTATCAGTGGTGCGA & CAAATCCAAGCTGTCTCTGTG \\
CDK2 & Real-time & CTCCTGGGCTCGAAATATTATTCCACAG & CCGGAAGAGCTGGTCAATCTCAGA \\
Cyclin A & Real-time & GCATGTCACCGTTCCTCCTT & CAGGGCATCTTCACGCTCTAT \\
CDK6 & Real-time & GGTCAGGTTGTTTGATGTGTGC & TATCCTTTATGGTTTCAGTGGG \\
Cyclin D & Real-time & CTACTACCGCCTCACACGCTTC & TCCTCCTCCTCTTCCTCCTCCT \\
CDK1 & Real-time & TCAAGTGGTAGCCATGAAAAAA & TAACCTGGAATCCTGCATAAGC \\
Cyclin B1 & Real-time & TGGCCTCACAAAGCACATGA & GCTGTGCCAGCGTGCTAATC \\
GAPDH & Real-time & GCAAATTCCATGGCACCGT & TCGCCCCACTTGATTTTGG \\
\hline
\end{tabular}

induced DNA damage response to induce cell cycle arrest and cell death, which may provide a strategy to increase the antitumor effect of PAB.

\section{Materials and methods}

Materials. PAB, which was purchased from the National Institute for the Control of Pharmaceutical and Biological Products (Beijing, China), was dissolved in dimethyl sulfoxide (DMSO) to make a stock solution. DMSO concentration was maintained at $<0.01 \%$ in all the cell cultures, and did not exert any detectable effect on cell growth or cell death. Propidium iodode (PI), phalloidin-tetramethylrhodamine B isothiocyanate, Hoechst 33258 and 3-(4,5-dimethylthiazol2-yl)-2,5-diphenyltetrazolium bromide (MTT) were purchased from Sigma Chemical Co. (St. Louis, MO, USA). TRIzol reagent and SuperScript ${ }^{\mathrm{TM}}$ III RT-PCR kit were purchased from Invitrogen (Carlsbad, CA, USA). Power SYBR-Green PCR Master Mix was purchased from ABI (Vernon, CA, USA). Caffeine was purchased from Shanghai YuanYe Biological Technology Co., Ltd. (Shanghai, China). The following mouse or rabbit antibodies were used in the western blot analyses: anti-CDK2 (Cell Signaling Technology, Inc., Danvers, MA, USA), anti-cyclin E1, anti-cyclin A2 (both from ProteinTech Group, Chicago, IL, USA), anti-CDK6, anti-cyclin D (both from Cell Signaling Technology, Inc.), anti-CDK1 (Boster Biological Technology Co., Ltd., Wuhan, China), anti-cyclin B1 (Santa Cruz Biotechnology, Inc., Santa Cruz, CA, USA), antiJNK1 and 2, anti-MAPK14 (p38) (both from Boster Biological Technology Co., Ltd.), anti-ERK1/2 (ProteinTech Group), antihistone H3 (Amersham Pharmacia Biotech, Piscataway, NJ, USA), anti- $\gamma$-h2ax (Cell Signaling Technology, Inc.), anti-actin, and alkaline phosphatase labeled-secondary antibodies (both obtained from Santa Cruz Biotechnology, Inc.).

Cell culture. The human glioblastoma A172 (CRL-1620 $\left.{ }^{\mathrm{TM}}\right)$ cell line was obtained from the American Type Culture Collection (ATCC; Manassas, VA, USA), and was cultured in Dulbecco's modified Eagle's medium (DMEM) (HyClone, Logan, UT, USA) supplemented with $10 \%$ fetal calf serum (FCS), 2 mM glutamine (both from Gibco-BRL, Grand Island, NY, USA), penicillin $(100 \mathrm{U} / \mathrm{ml})$ and streptomycin $(100 \mu \mathrm{g} / \mathrm{ml})$, and maintained at $37^{\circ} \mathrm{C}$ with $\mathrm{CO}_{2}$ in a humidified atmosphere.
Cell growth inhibition test. Inhibition of cell growth was determined by MTT assay. A172 cells $\left(1.0 \times 10^{4}\right.$ cells/well) were seeded into 96-well culture plates (Nunc, Roskilde, Denmark). After $24 \mathrm{~h}$ of incubation, different concentrations of PAB were added to the plates, and $0 \mu \mathrm{M}$ PAB was used as a control, and other doses as samples. Following incubation, cell growth was measured at different time points by addition of $20 \mu \mathrm{l}$ MTT $(5 \mathrm{mg} / \mathrm{ml})$ at $37^{\circ} \mathrm{C}$ for $2 \mathrm{~h}$, and DMSO $(150 \mu \mathrm{l})$ was added to dissolve the formazan crystals. Absorbance was measured at $492 \mathrm{~nm}$ with an enzyme-linked immunosorbent assay plate reader (Bio-Rad, Hercules, CA, USA). The percentage of inhibition was calculated as follows:

Cell death $(\%)=\left[\mathrm{A}_{492}\right.$ (control) $-\mathrm{A}_{492}($ sample $\left.)\right] / \mathrm{A}_{492}($ control $) \times 100 \%$

Microtubule aggregation by fluorescence staining. A172 cells $\left(5 \times 10^{5}\right)$ were placed on a coverslip in a 6-well plate. After $24 \mathrm{~h}$ of cell culture, they were treated with $4 \mu \mathrm{M}$ PAB for 24 or $48 \mathrm{~h}$, and then washed with PBS, fixed in $3.7 \%$ formaldehyde, and then rinsed three times in $1 \mathrm{X}$ PBS. Next, $0.8 \%$ Triton X-100 was added for $15 \mathrm{~min}$, and $5 \mu \mathrm{g} / \mathrm{ml}$ phalloidin-tetramethylrhodamine B isothiocyanate staining was performed for $40 \mathrm{~min}$, followed by one rinse in 1X PBS and then staining with $5 \mathrm{mg} / 1$ Hoechst 33258 for $30 \mathrm{~min}$. The intensity of red staining was measured by fluorescence microscopy at excitation wavelength $584 \mathrm{~nm}$ with emission filter $607 \mathrm{~nm}$ (Leica, Nusslich, Germany). Nuclear changes were observed by fluorescence microscopy at excitation wavelength $350 \mathrm{~nm}$ with emission filter $460 \mathrm{~nm}$ (Leica).

Cell migration. A172 cells were cultured for $24 \mathrm{~h}$, and then a line was scratched randomly with a pipette tip. Lines with the same width were chosen, and the width was recorded at 0,12 , 24, 36 and $48 \mathrm{~h}$ after control medium or PAB treatment by phase contrast microscopy (Leica).

Flow cytometric analysis of cell cycle distribution. A172 cells were cultured for $24 \mathrm{~h}$, and then collected at 0, 12, 24, 36 and $48 \mathrm{~h}$ after control medium or PAB treatment. Collected A172 cells $\left(1.0 \times 10^{6}\right)$ were harvested and rinsed with PBS. The cell pellets were fixed in $70 \%$ ethanol at $4{ }^{\circ} \mathrm{C}$ overnight. After washing twice with PBS, the cells were stained with $1.0 \mathrm{ml}$ of PI solution containing PI $50 \mathrm{mg} / \mathrm{l}$, RNase A $1 \mathrm{~g} / \mathrm{l}$ and $0.1 \%$ Triton $\mathrm{X}-100$ in sodium citrate $3.8 \mathrm{mmol} / 1$, followed 


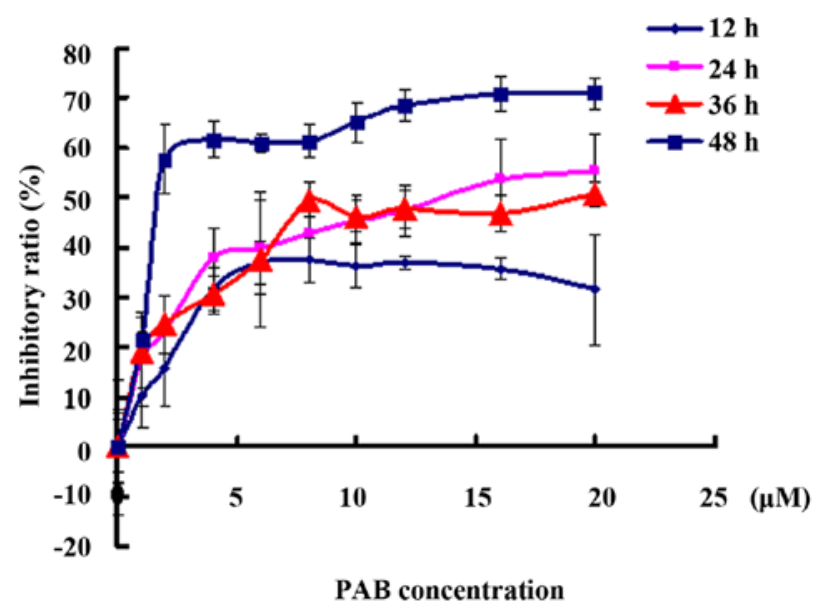

Figure 1. The inhibitory effect of different doses of pseudolaric acid B (PAB) on A172 cell growth at different times. The cells $\left(1 \times 10^{4}\right.$ cells/well) were incubated with DMEM for $24 \mathrm{~h}$, and then DMEM was replaced with different doses of PAB for 12, 24, 36 and $48 \mathrm{~h}$. Growth inhibition was evaluated by MTT assay. Mean $\pm \mathrm{SD}, \mathrm{n}=3$.
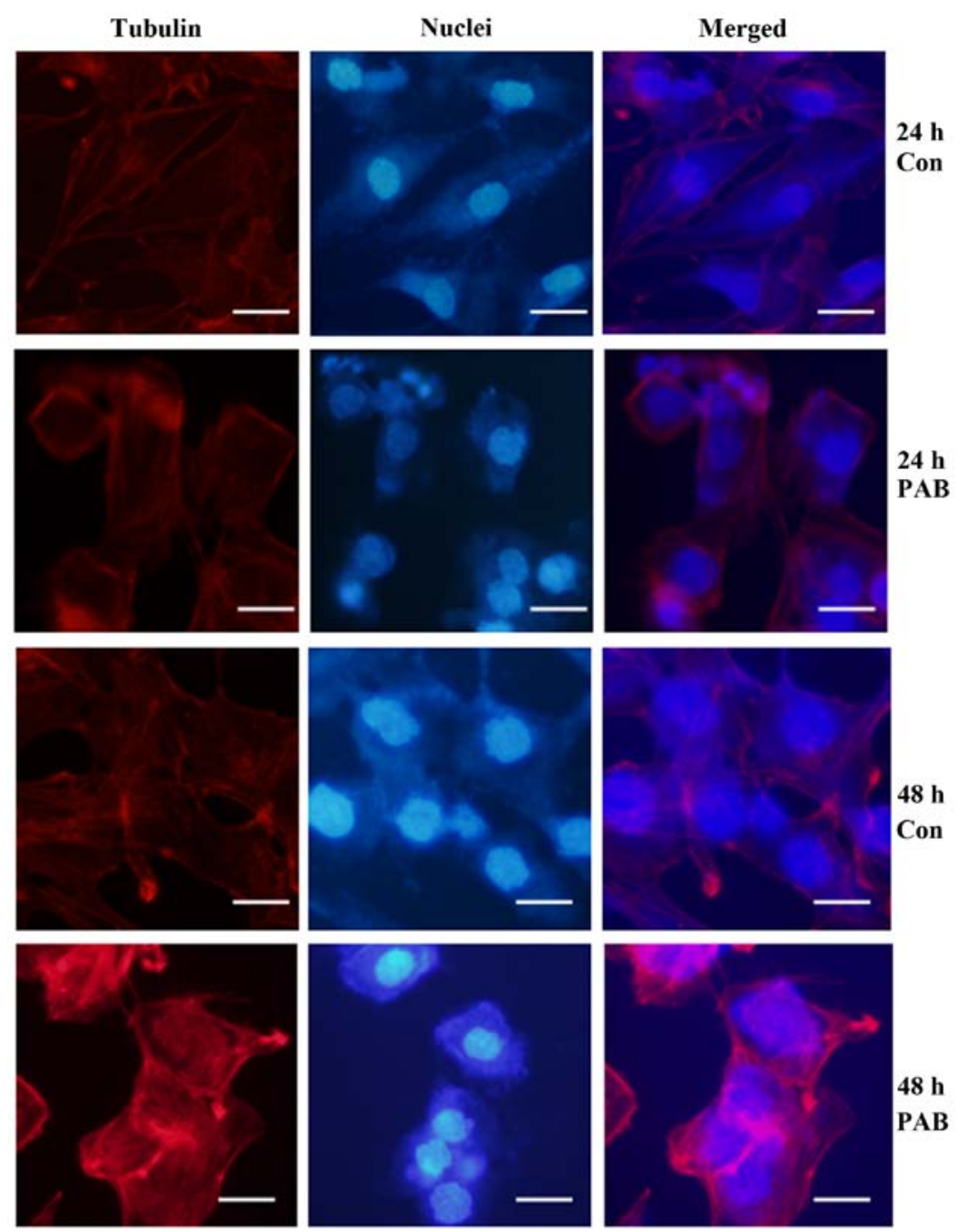

Figure 2. Tubulin distribution analysis in pseudolaric acid B (PAB)-treated A172 cells by fluorescence microscopy. A172 cells were treated with $4 \mu \mathrm{M}$ of PAB for 24 and $48 \mathrm{~h}$. Tubulin distribution and nuclear alteration analysis of PAB-treated A172 cells were assessed by fluorescence microscopy after phalloidin-tetramethylrhodamine B isothiocyanate and Hoechst 33258 staining. Merged images of tubulin and DNA are shown. Data are representative of three individual experiments $(\mathrm{n}=3)$. Con, control. Scale bar, $15 \mu \mathrm{m}$.

by incubation on ice in the dark for $30 \mathrm{~min}$. The samples were analyzed by a FACScan flow cytometer (Becton-Dickinson, Franklin Lakes, NJ, USA).
Quantitative real-time PCR. RNA was extracted from cells treated with control medium and PAB using TRIzol reagent (Gibco-BRL, Rockville, MD, USA) and isolated as specified 
by the manufacturer. The RNA was treated with DNAse (DNase I-RNase-Free; Ambion, Foster City, CA, USA) to remove any contaminating DNA; $200 \mathrm{ng}$ of total RNA was reverse-transcribed with oligo-dT primers using the High Capacity cDNA RT kit (Applied Biosystems, Foster City, CA, USA) in a $20 \mu \mathrm{l}$ cDNA reaction, as specified by the manufacturer. For quantitative PCR, the template cDNA was added to a $20 \mu \mathrm{l}$ reaction with SYBR-Green PCR Master Mix (Applied Biosystems) and $0.2 \mu \mathrm{M}$ of the primers was added (primers are listed in Table I). Amplification was carried out using an ABI PRISM 7000 for 40 cycles under the following conditions: initial denaturation at $95^{\circ} \mathrm{C}$ for $10 \mathrm{~min}$, plus 40 cycles of $95^{\circ} \mathrm{C}$ for $15 \mathrm{sec}$, followed by $60^{\circ} \mathrm{C}$ for $1 \mathrm{~min}$. The fold changes were calculated relative to GAPDH using the $\Delta \Delta \mathrm{Ct}$ method for target gene mRNA analysis.

Observation of morphologic changes by light microscopy. A172 cells $\left(5 \times 10^{5}\right.$ cells/well) were cultured into a 6 -well plate for $12 \mathrm{~h}$. Then, the cells were treated with $4 \mu \mathrm{M}$ PAB and/or caffeine for $0,12,24,36$ and $48 \mathrm{~h}$, and morphologic changes were observed by phase contrast microscopy (Leica).

Western blot analysis of protein expression. A172 cells $\left(1 \times 10^{6}\right)$ were cultured in a $25-\mathrm{ml}$ culture bottle for the indicated time, and then were treated with $4 \mu \mathrm{M}$ PAB for the indicated time. Both adherent and floating cells were collected and frozen at $-80^{\circ} \mathrm{C}$. Western blot analysis was performed for total proteins as described previously (5). Protein expression was detected using primary polyclonal antibody $(1: 1,000)$ followed by a corresponding AP-conjugated secondary antibody diluted 1:1,000. Proteins were visualized using NBT and BCIP.

Statistical analysis. All data represent at least three independent experiments, and are expressed as mean \pm SD. P-values $<0.001$ were considered to represent statistically significant differences.

\section{Results}

Inhibitory effect of PAB on A172 cells. To detect the inhibitory effect of PAB on neuroglioma cell proliferation, MTT assay was carried out. PAB treatment had an inhibitory effect on the A172 cells in a time- and dose-dependent manner (Fig. 1). In addition, $4 \mu \mathrm{M}$ PAB inhibited cell growth with an inhibitory ratio of $40 \%$ at $48 \mathrm{~h}$, as found in previous studies $(5,6)$. Thus, we chose $4 \mu \mathrm{M}$ PAB in the following experiments.

$P A B$ promotes the aggregation of microtubule fiber. $\mathrm{PAB}$ exerts its function by influencing microtubule fiber aggregation (17). We found that PAB treatment promoted the uneven aggregation of microtubule fibers with more obvious red staining, while control cells showed even aggregation of microtubule fibers (Fig. 2). Therefore, PAB influenced cell microtubule fiber to exert its function.

$P A B$ inhibits cell migration. Tumor cells with a high ability for migration are difficult to treat. In the migration assay, we confirmed that A172 cells had a high migration ability since with increasing time the scratch wound line disappeared. Meanwhile, after PAB treatment, the scratch wound line that
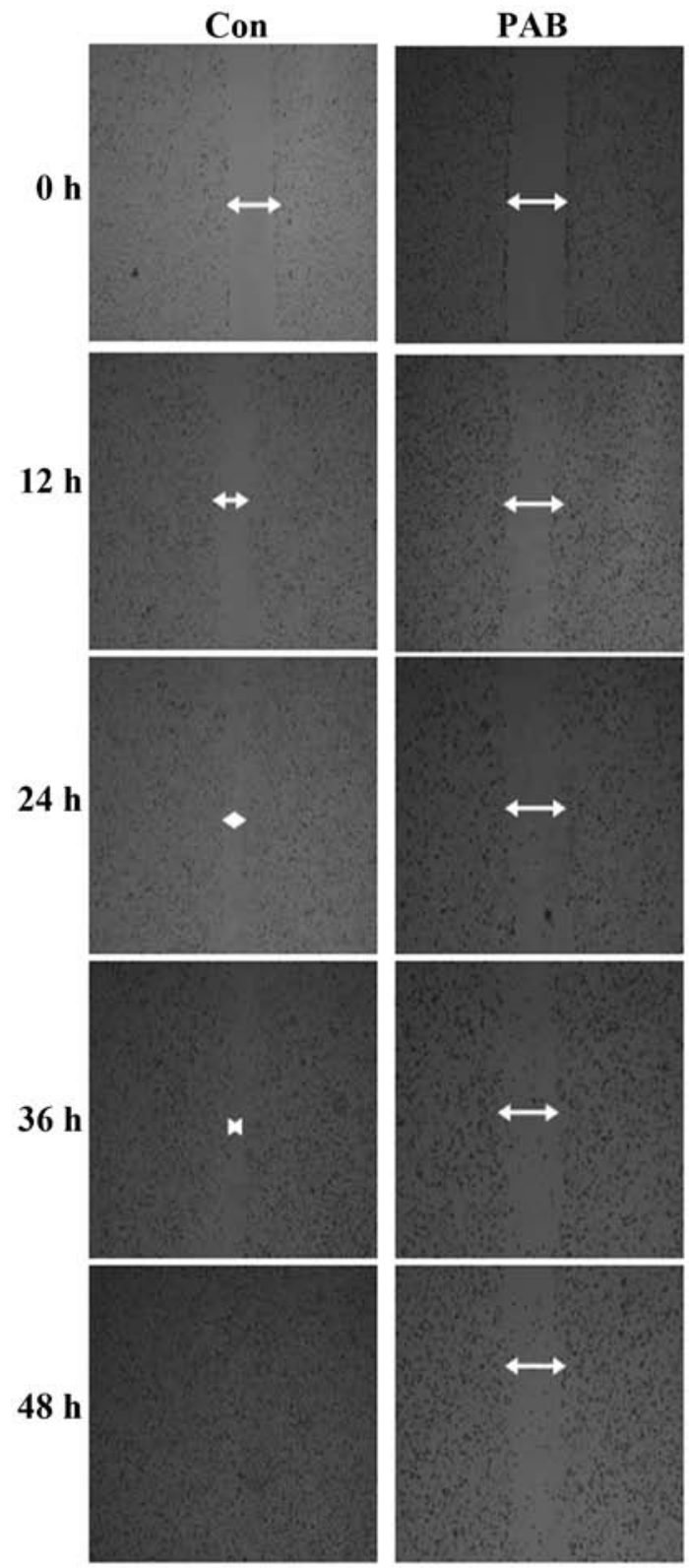

Figure 3. Pseudolaric acid B (PAB) inhibits cell migration. We used a pipette to scratch an arbitrary line in the control and PAB-treated cells, and at 12 , 24,36 and $48 \mathrm{~h}$, the width was recorded. Data are representative of three individual experiments $(\mathrm{n}=3)$. Con, control.

remained was wider than that of the control cells (Fig. 3). Therefore, A172 cells had a high ability of migration, and PAB inhibited the cell migration of these cells.

$P A B$ induces $G 2 / M$ cell cycle arrest. It was observed that from $12 \mathrm{~h}, \mathrm{PAB}$ treatment induced obvious $\mathrm{G} 2 / \mathrm{M}$ cell cycle arrest. At $24 \mathrm{~h}$, in the control group, the percentage of cells in the $\mathrm{G} 2 / \mathrm{M}$ phases was $3.70 \pm 1.47 \%$, while after PAB treatment it was $45.82 \pm 0.64 \%$; at $36 \mathrm{~h}$ in the control group, the percentage of cells was $2.97 \pm 1.10 \%$, while after PAB treatment it was $64.83 \pm 4.27 \%$; at $48 \mathrm{~h}$ in the control group the percentage of cells was $3.45 \pm 1.29 \%$, while after PAB treatment it was $56.98 \pm 2.14 \%$ (Fig. 4A). Therefore, PAB induced G2/M arrest. In addition, at $24 \mathrm{~h}$ after PAB treatment the percentage of cells in the G0/G1 phase was $4.50 \pm 3.98 \%$, while at $36 \mathrm{~h}$ after PAB treatment the percentage of G0/G1 cells was $8.39 \pm 1.46 \%$, and 
A

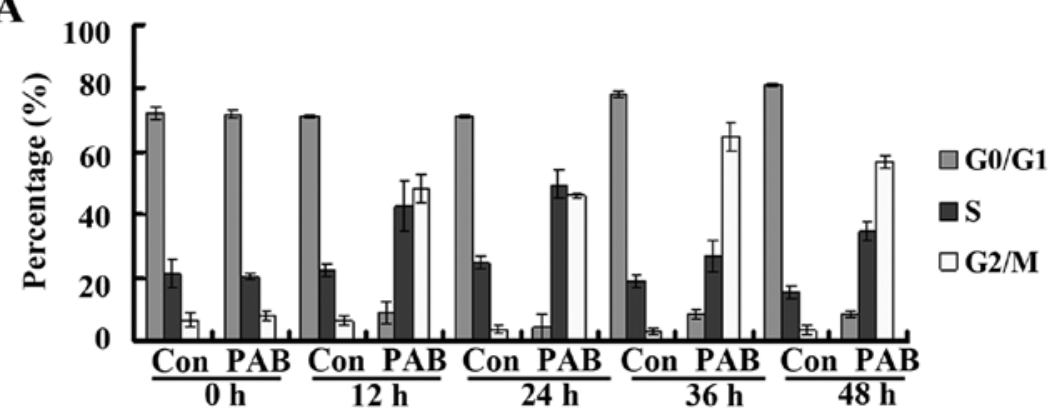

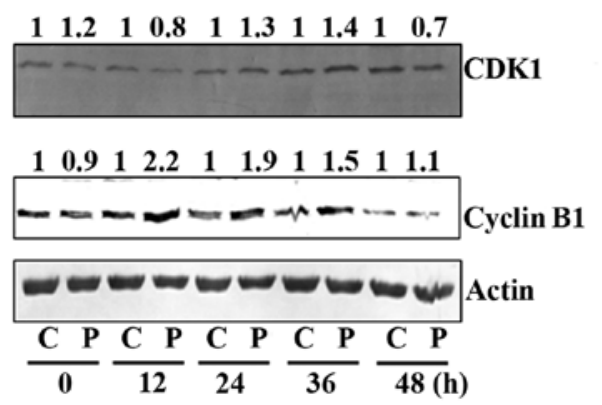

B

C

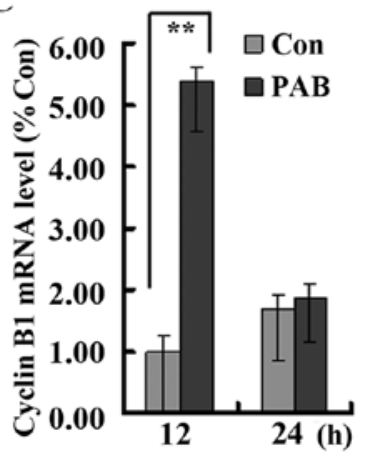

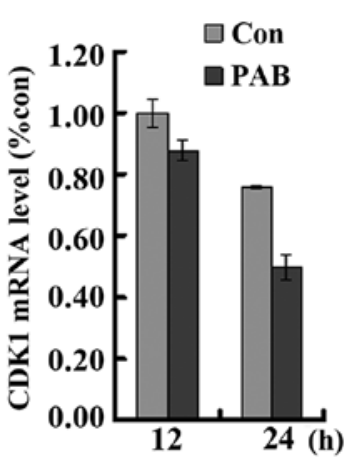

Figure 4. Pseudolaric acid B (PAB) promotes cell cycle arrest. (A) At 12, 24, 36 and 48 h, PAB induced obvious cell cycle arrest. Flow cytometric analysis showed that from 12 to $48 \mathrm{~h}, 4 \mu \mathrm{M}$ PAB induced obvious cell cycle arrest. Mean $\pm \mathrm{SD}, \mathrm{n}=3$. (B) PAB regulated cyclin B1 and CDK1 expression. At 12 and $48 \mathrm{~h}$ after PAB treatment, the cells were analyzed and western blotting was performed for protein expression. Actin is shown as a loading control. The number above each western blot band is provided, which were standardized using actin and normalized to 1.0 in the control group. C, control; P, PAB. (C) At 12 and $48 \mathrm{~h}$ after PAB treatment, intracellular cyclin B1 and CDK1 mRNA levels were detected in the control group (con) or PAB treatment group by real-time quantitative PCR. The results were standardized using GAPDH mRNA as a control and normalized to 1.0 in the control group. The results represent the mean \pm SD of three independent experiments; ${ }^{* *} \mathrm{P}<0.01$.

at $48 \mathrm{~h}$ after $\mathrm{PAB}$ treatment the percentage of $\mathrm{S}$ phase cells $(34.65 \pm 2.82 \%)$ was increased compared to the PAB group at $36 \mathrm{~h}(26.77 \pm 3.36 \%)$. Therefore, PAB induced cell cycle slippage from $\mathrm{G} 2 / \mathrm{M}$ into $\mathrm{G} 0 / \mathrm{G} 1$ and then into $\mathrm{S}$ phase. To further investigate the mechanism underlying the effect on the cell cycle by $\mathrm{PAB}$, cyclin $\mathrm{B} 1$ and CDK1 expression was detected owning to the fact that the cyclin $\mathrm{B} 1 / \mathrm{CDK} 1$ complex regulates $\mathrm{G} 2 / \mathrm{M}$ process. It was found that from $12 \mathrm{~h}$, the expression of cyclin B1 was increased after PAB treatment compared to the control treatment, and the expression of CDK1 was increased from $24 \mathrm{~h}$, while at $48 \mathrm{~h}$, the expression of CDK1 and cyclin $\mathrm{B} 1$ after $\mathrm{PAB}$ treatment was not increased compared to the control treatment (Fig. 4B). Therefore, PAB by regulating cyclin $\mathrm{B} 1 / \mathrm{CDK} 1$ complex expression induced cell cycle arrest at G2/M until $36 \mathrm{~h}$, and at $48 \mathrm{~h}$ cyclin B1/CDK1 complex expression was consistent with the cell cycle slippage. To explain the expression alteration of the cyclin B1/CDK1 complex, the transcription of this complex was analyzed. It was found that the mRNA level of cyclin B1 in the PAB group was 5.39 times higher than that in the control group after a 12 -h treatment $(\mathrm{P}<0.01)$, while at $48 \mathrm{~h}$, there was no obvious difference. For CDK1, at 12 and $48 \mathrm{~h}$ after PAB treatment, there was no difference with the control treatment (Fig. 4C). Therefore, PAB regulated protein expression through different mechanisms, partly through the transcriptional level.

Meanwhile, the effect of PAB on S phase and G0/G1-related protein expression was observed. It was found that in regards to $\mathrm{S}$ phase-related proteins, $\mathrm{PAB}$ decreased the expression of cyclin E at 24 and $36 \mathrm{~h}$ after PAB treatment, but at $48 \mathrm{~h}$ PAB treatment increased the expression of cyclin E, and PAB decreased the expression of CDK2 from 12 to $36 \mathrm{~h}$ after PAB treatment, but at $48 \mathrm{~h}, \mathrm{PAB}$ treatment had no effect on CDK2 expression (Fig. 5A), which was consistent with the slippage into $\mathrm{S}$ phase at $48 \mathrm{~h}$ after $\mathrm{PAB}$ treatment. However, $\mathrm{PAB}$ treatment had no effect on the expression of cyclin A from 12 to $48 \mathrm{~h}$ compared to control treatment (Fig. 5A), indicating that PAB regulated cell cycle progression, possibly independent of cyclin A expression. In addition, we also assessed the transcription of them to explain the alteration at the protein level, and we found that the mRNA level of CDK2 was decreased after PAB treatment at $12 \mathrm{~h}$ compared to the control treatment, and the mRNA level of cyclin $\mathrm{E}$ was increased after PAB treatment at $48 \mathrm{~h}$ compared to the control treatment, which could partly explain the alteration of CDK2 and cyclin E (Fig. 5C). For G0/G1-related protein expression, it was found that at $36 \mathrm{~h}$ after PAB treatment, the expression of cyclin D was increased, but at $48 \mathrm{~h}$, the expression of cyclin D was decreased (Fig. 5B), which was consistent with the slippage into $S$ phase at $36 \mathrm{~h}$, and then into $S$ phase at $48 \mathrm{~h}$ after PAB treatment. The expression of CDK6 was not affected when compared to the control treatment (Fig. 5B), indicating that $\mathrm{PAB}$ regulated cyclin $\mathrm{D}$ expression to regulate the activity of cyclin D and CDK6 complex. In addition, at 12 and $48 \mathrm{~h}, \mathrm{PAB}$ did not affect the mRNA levels of cyclin D and CDK6 compared to the levels noted in the control treatment group (Fig. 5C). Therefore, $\mathrm{PAB}$ regulates protein expression, but not at the level of transcription. 
A

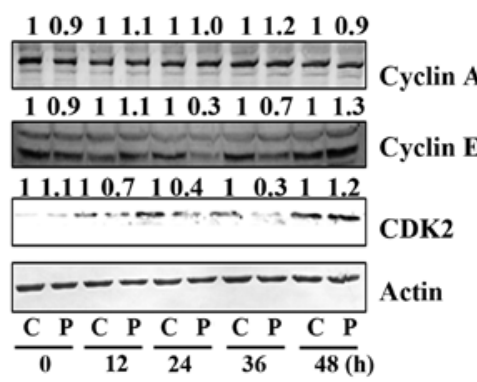

B

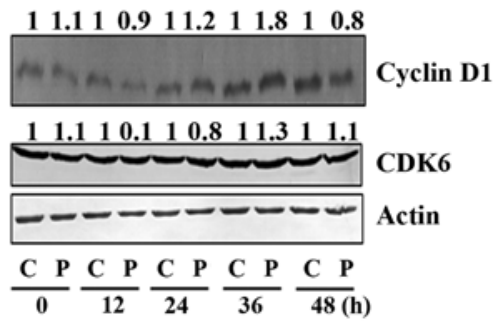

C

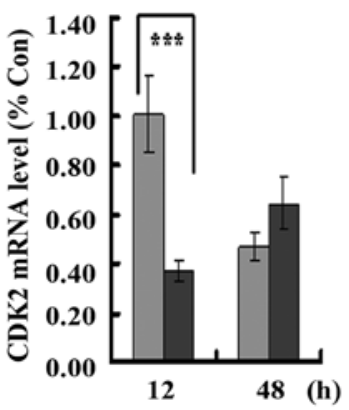

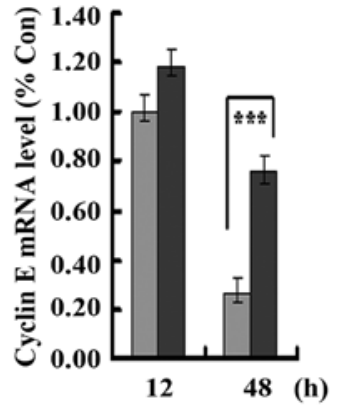

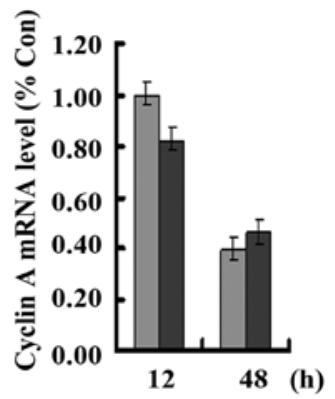

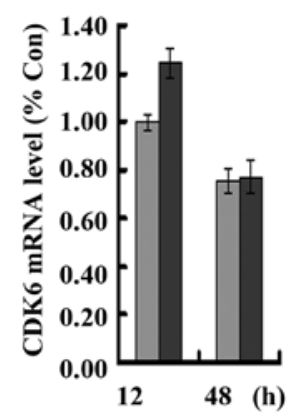

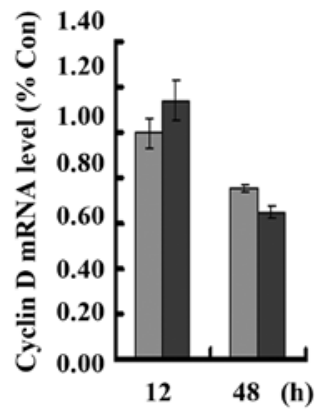

Figure 5. Pseudolaric acid B (PAB) regulates expression of S and G0/G1 phase-related proteins. (A and B) At 12 and $36 \mathrm{~h}$ after PAB treatment, the cells were analyzed and western blotting was performed for cyclin A1, cyclin E1, CDK2, cyclin D1 and CDK6 protein expression. Actin is shown as a loading control. The number above each western blot band is provided, which was standardized using actin and normalized to 1.0 in the control group. C, control; P, PAB. (C) At 12 and $48 \mathrm{~h}$ after PAB treatment, intracellular cyclin A1 and E1, CDK2, cyclin D1 and CDK6 mRNA levels were detected in the control group (Con) or PAB treatment group by real-time quantitative PCR. The results were standardized using GAPDH mRNA as a control and normalized to 1.0 in the control group. The results represent the mean \pm SD of three independent experiments; ${ }^{* * *} \mathrm{P}<0.001$.

$P A B$ induces cell death through MAPK protein. To further confirm the mechanism underlying the inhibition of cell proliferation by $\mathrm{PAB}$, in the present study we confirmed the effect of PAB on cell death. From morphologic analysis, it was found that from $12 \mathrm{~h}$, compared to the control group, the cell number was decreased by PAB treatment. Meanwhile it was found that in the PAB treatment group, the number of floating cells was increased compared to the number noted in the control group, indicating that PAB induced cell death (Fig. 6A). Then, we further analyzed the mechanism of cell death, and it was confirmed that from 12 to $48 \mathrm{~h}$, the expression levels of JNK and ERK were decreased by PAB treatment compared to these levels in the control treatment group, while the expression of $\mathrm{p} 38$ was increased by PAB (Fig. 6B). Therefore, by regulating the expression of MAPK, PAB induced cell death in the A172 cells.

$P A B$ induces cell death through the DNA damage response. Cell death and cell cycle arrest usually are downstream of the DNA damage response (10). In the present study, we found that PAB induced cell death and cell cycle arrest, and we aimed to ascertain whether PAB induces a DNA damage response.
Thus, the expression of $\gamma \mathrm{H} 2 \mathrm{AX}$, which is the marker of DNA damage response, was determined. It was found that PAB treatment increased the expression of $\gamma \mathrm{H} 2 \mathrm{AX}$ at 12, 24, 36 and $48 \mathrm{~h}$ compared to the expression levels noted in the control treatment group (Fig. 7A). Then, we analyzed the effect of caffeine on the inhibitory ratio of $\mathrm{PAB}$, and it was found that at $24 \mathrm{~h}$, caffeine treatment decreased the inhibitory ratio from $35.90 \pm 5.67$ to $26.38 \pm 2.52 \%$, and at $48 \mathrm{~h}$ caffeine treatment decreased the inhibitory ratio from $44.12 \pm 3.56$ to $21.79 \pm 1.89 \%$. Therefore, $\mathrm{PAB}$ activated the DNA damage response to induce apoptosis (Fig. 7B). Subsequently, caffeine was used to inhibit the DNA damage response, and it was found that $2 \mathrm{mM}$ caffeine treatment inhibited cell death induced by PAB at $24 \mathrm{~h}$ and $48 \mathrm{~h}$ compared to that noted in the PAB treatment group (Fig. 7C).

\section{Discussion}

Glioblastoma is the most common cancer of the brain and displays an increasing incidence. Despite major advances in the field, there is no curative therapy for glioblastoma, to date (18). Pseudolaric acid B (PAB), a diterpene acid isolated 
A
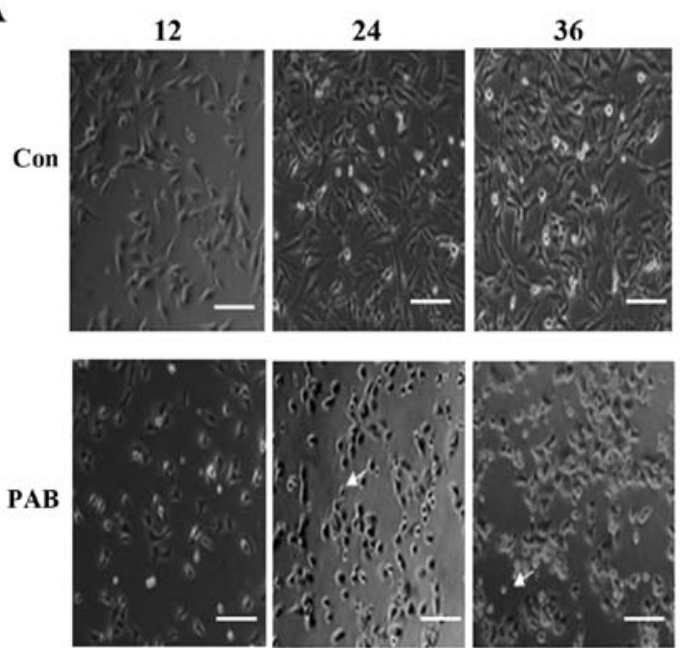

48 (h)
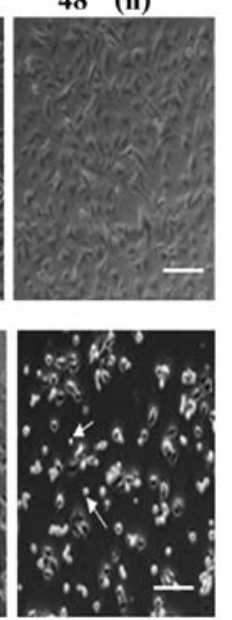

B
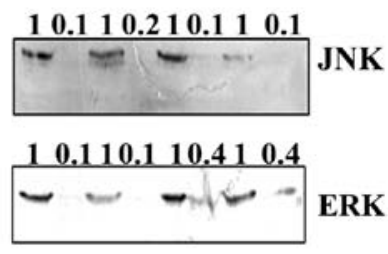

11.611 .011 .211 .1

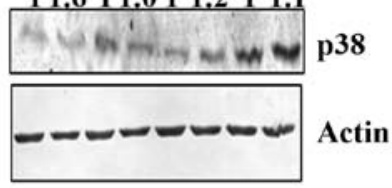

C P C P C P C P

$\begin{array}{lllll}\overline{12} & \overline{24} & \overline{36} & \overline{48} & \text { (h) }\end{array}$

Figure 6. Pseudolaric acid B (PAB) induces cell death through MAPK protein. (A) After 12, 24, 36 and $48 \mathrm{~h}$ of PAB treatment, morphological changes in A172 cells were visualized under phase contrast microscopy; Scale bar, $100 \mu \mathrm{m}$. (B) Expression of MAPK protein. Actin is shown as a loading control. The number above each western blot band is provided, which was standardized using actin and normalized to 1.0 in the control group. C, control; P, PAB. Data are representative of three individual experiments $(n=3)$.

A

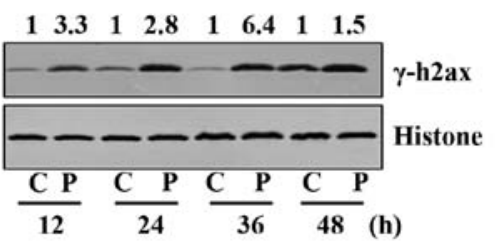

B

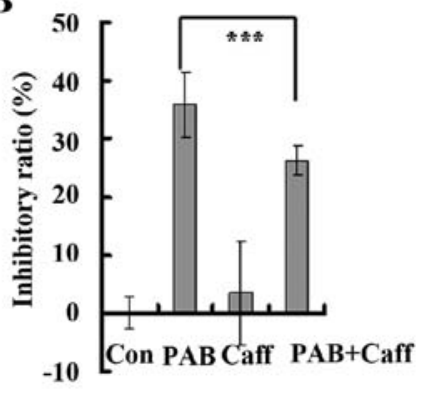

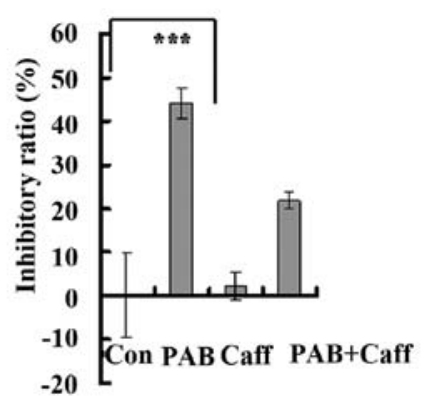

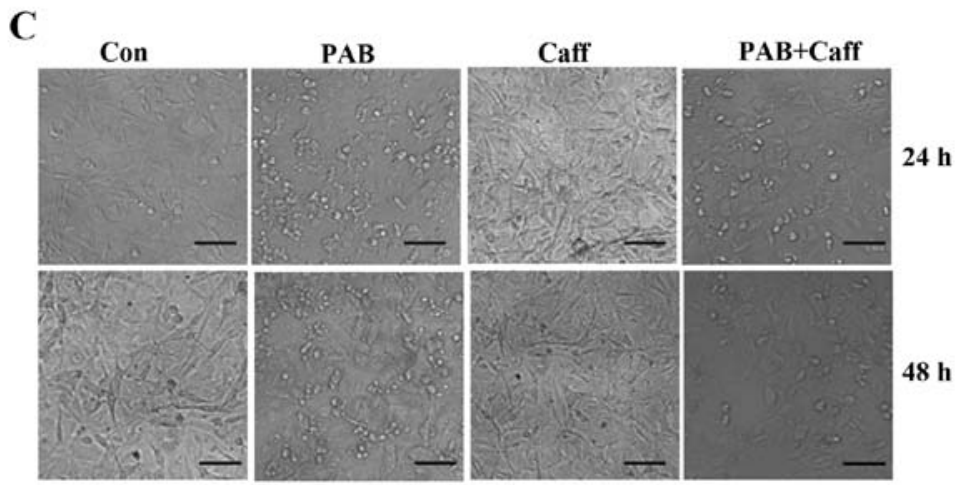

Figure 7. Pseudolaric acid B (PAB) induces DNA damage response for cell death. (A) The expression of $\gamma-\mathrm{H} 2 \mathrm{AX}$ protein after $0,12,24,36$ and $48 \mathrm{~h}$ of PAB treatment. Histone is shown as a loading control. The number above each western blot band is provided, which was standardized using histone and normalized to 1.0 in the control group. Data are representative of three individual experiments ( $n=3$ ). (B) The effect of caffeine, an inhibitor of DNA damage response, on cell death induced by PAB in A172 cells at 24 and $48 \mathrm{~h}$ as evaluated by MTT method. Mean $\pm \mathrm{SD}, \mathrm{n}=3 ;{ }^{* * *} \mathrm{P}<0.001$. (C) After 24 and $48 \mathrm{~h}$ of $\mathrm{PAB}$ and/or $2 \mathrm{mM}$ caffeine treatment morphological changes were visualized in A172 cells under phase contrast microscopy; Scale bar, $50 \mu \mathrm{m}$. C, control; P, PAB; Caff, caffeine.

from the root and trunk bark of Pseudolarix kaempferi Gordon was found to exert antitumor effect on different cell lines (1-6), and in the present study we explored the role of $\mathrm{PAB}$ in glioblastoma.

Firstly, we found that PAB inhibited glioblastoma cell growth in a time- and dose-dependent manner, indicating that
PAB had potential anti-glioblastoma function. Similar to the role of PAB in other cell lines $(17,19,20)$, PAB mainly affected microtubule aggregation in glioblastoma to inhibit cancer cell growth. It has been reported that glioblastoma cell migration and invasion occur at multiple stages of cancer progression and are a clinical obstacle for therapy. Thus, suppression 
of glioblastoma cell migration and invasion may provide an effective therapeutic strategy (21). The present study confirmed that PAB inhibited the migration of glioblastoma, which is another advantage of PAB in the course of antitumor therapy.

Cell cycle arrest is an important mechanism by which to inhibit cell growth. We found that from $12 \mathrm{~h}$, PAB treatment obviously increased the percentage of cells in the G2/M phase compared to the percentage in the control treatment group, indicating that PAB had the ability to induce cell cycle arrest to inhibit cell growth. In addition, PAB treatment increased the expression of cyclin B1/CDK1 complex expression, which was consistent with the profile of G2/M arrest. Meanwhile, PAB treatment increased the mRNA level of cyclin B1 at $12 \mathrm{~h}$, indicating that $\mathrm{PAB}$ affected cyclin $\mathrm{B} 1$ transcription to regulate protein expression, and $\mathrm{PAB}$ did not affect CDK1 transcription, indicating that $\mathrm{PAB}$ regulated protein expression through different mechanisms. Meanwhile it was noted that at $36 \mathrm{~h}$ after PAB treatment, the percentage of $\mathrm{G} 0 / \mathrm{G} 1$ phase cells was increased compared to $24 \mathrm{~h}$ after PAB treatment, and at $48 \mathrm{~h}$ after PAB treatment, the percentage of $\mathrm{S}$ phase cells was increased compared to $36 \mathrm{~h}$ after PAB treatment, indicating that at $36 \mathrm{~h}$, cell cycle slippage into G0/G1 occurred, and at $48 \mathrm{~h}$ cell cycle slippage into $\mathrm{S}$ occurred. Furthermore, expression levels of cell cycle-related G0/G1 and S phase proteins were observed, and it was found that at $36 \mathrm{~h}$ after PAB treatment, the expression of cyclin D1 was increased compared to that in the control treatment group, and at $48 \mathrm{~h}$, the expression of cyclin E and CDK2 was increased compared to levels in the control treatment group, which was consistent with the results of cell cycle slippage.

Cell death is another mechanism of inhibiting cell growth. In the present study, based on morphologic analysis, we found that PAB treatment promoted cell death with increasing time, and PAB treatment inhibited the expression of JNK and ERK, and increased the expression of p38 compared to levels in the control treatment group. Therefore, PAB regulated corresponding protein expression to induce cell death. Meanwhile DNA damage response is commonly activated to promote cell death. We found that PAB treatment increased the expression of $\gamma-\mathrm{H} 2 \mathrm{AX}$, which is the marker of DNA damage response. Therefore, PAB treatment activated the DNA damage response. In addition, caffeine was used by us to inhibit the DNA damage response. We found that caffeine reversed the effect of PAB to protect cells from cell death, and correspondingly to decrease the inhibitory ratio; thus PAB activated the DNA damage response to induce cell death, which provided a target to increase the antitumor effect of PAB. In conclusion, $\mathrm{PAB}$ is a candidate for anti-glioblastoma treatment.

\section{Acknowledgements}

The present study was supported by funding from the National Natural Science Foundation of China (no. 81301416), the Postdoctoral Science Foundation of China (nos. 2014M561302 and 2015T80299), the Norman Bethune Program of Jilin University (no. 2015202), the Jilin Provincial Science and Technology Department (nos. 20140204004YY and 20160414025GH), and the Department of Human Resources and Social Security of Jilin Province (no. 2016014).

\section{References}

1. Gong X, Wang M, Tashiro S, Onodera S and Ikejima T: Involvement of JNK-initiated p53 accumulation and phosphorylation of p53 in pseudolaric acid B induced cell death. Exp Mol Med 38: 428-434, 2006.

2. Gong XF, Wang MW, Tashiro S, Onodera S and Ikejima T: Pseudolaric acid B induces apoptosis through p53 and Bax/Bcl-2 pathways in human melanoma A375-S2 cells. Arch Pharm Res 28: 68-72, 2005.

3. Pan DJ, Li ZL, Hu CQ, Chen K, Chang JJ and Lee KH: The cytotoxic principles of Pseudolarix kaempferi: Pseudolaric acid-A and -B and related derivatives. Planta Med 56: 383-385, 1990.

4. Yu J, Li X, Tashiro S, Onodera S and Ikejima T: Bcl-2 family proteins were involved in pseudolaric acid B-induced autophagy in murine fibrosarcoma L929 cells. J Pharmacol Sci 107: 295-302, 2008

5. Yu JH, Cui Q, Jiang YY, Yang W, Tashiro S, Onodera S and Ikejima T: Pseudolaric acid B induces apoptosis, senescence, and mitotic arrest in human breast cancer MCF-7. Acta Pharmacol Sin 28: 1975-1983, 2007.

6. Yu JH, Wang HJ, Li XR, Tashiro S, Onodera S and Ikejima T: Protein tyrosine kinase, JNK, and ERK involvement in pseudolaric acid B-induced apoptosis of human breast cancer MCF-7 cells. Acta Pharmacol Sin 29: 1069-1076, 2008.

7. Shakur SF, Bit-Ivan E, Watkin WG, Merrell RT and Farhat HI Multifocal and multicentric glioblastoma with leptomeningeal gliomatosis: A case report and review of the literature. Case Rep Med 2013: 132679, 2013.

8. Walker C, Baborie A, Crooks D, Wilkins S and Jenkinson MD: Biology, genetics and imaging of glial cell tumours. Br J Radiol 84: S90-S106, 2011.

9. Parsons DW, Jones S, Zhang X, Lin JC, Leary RJ, Angenendt P, Mankoo P, Carter H, Siu IM, Gallia GL, et al: An integrated genomic analysis of human glioblastoma multiforme. Science 321: 1807-1812, 2008.

10. Lozano G and Elledge SJ: p53 sends nucleotides to repair DNA. Nature 404: 24-25, 2000.

11. Li FF, Yi S, Wen L, He J, Yang LJ, Zhao J, Zhang BP, Cui GH and Chen Y: Oridonin induces NPM mutant protein translocation and apoptosis in NPM1c+ acute myeloid leukemia cells in vitro. Acta Pharmacol Sin 35: 806-813, 2014.

12. Qi M, Yao G, Fan S, Cheng W, Tashiro S, Onodera S and Ikejima T: Pseudolaric acid B induces mitotic catastrophe followed by apoptotic cell death in murine fibrosarcoma L929 cells. Eur J Pharmacol 683: 16-26, 2012.

13. Klekotka PA, Santoro SA, Wang H and Zutter MM: Specific residues within the alpha 2 integrin subunit cytoplasmic domain regulate migration and cell cycle progression via distinct MAPK pathways. J Biol Chem 276: 32353-32361, 2001.

14. Xia Z, Dickens M, Raingeaud J, Davis RJ and Greenberg ME: Opposing effects of ERK and JNK-p38 MAP kinases on apoptosis. Science 270: 1326-1331, 1995.

15. Yoon S and Seger R: The extracellular signal-regulated kinase: Multiple substrates regulate diverse cellular functions. Growth Factors 24: 21-44, 2006.

16. Hartwell LH and Weinert TA: Checkpoints: Controls that ensure the order of cell cycle events. Science 246: 629-634, 1989.

17. Yu J, Ren P, Zhong T, Wang Y, Yan M, Xue B, Li R, Dai C, Liu C, Chen G, et al: Pseudolaric acid B inhibits proliferation in SW579 human thyroid squamous cell carcinoma. Mol Med Rep 12: 7195-7202, 2015.

18. Liu X, Chong Y, Tu Y, Liu N, Yue C, Qi Z, Liu H, Yao Y, Liu H, Gao S, et al: CRM1/XPO1 is associated with clinical outcome in glioma and represents a therapeutic target by perturbing multiple core pathways. J Hematol Oncol 9: 108, 2016.

19. Tong YG, Zhang XW, Geng MY, Yue JM, Xin XL, Tian F, Shen X, Tong LJ, Li MH, Zhang C, et al: Pseudolarix acid B, a new tubulin-binding agent, inhibits angiogenesis by interacting with a novel binding site on tubulin. Mol Pharmacol 69: 1226-1233, 2006.

20. Wong VK, Chiu P, Chung SS, Chow LM, Zhao YZ, Yang BB and Ko BC: Pseudolaric acid B, a novel microtubule-destabilizing agent that circumvents multidrug resistance phenotype and exhibits antitumor activity in vivo. Clin Cancer Res 11: 6002-6011, 2005.

21. Liu B, Dong H, Lin X, Yang X, Yue X, Yang J, Li Y, Wu L, Zhu X, Zhang S, et al: RND3 promotes Snail 1 protein degradation and inhibits glioblastoma cell migration and invasion. Oncotarget 7: 82411-82423, 2016. 